\title{
A!
}

This is an electronic reprint of the original article.

This reprint may differ from the original in pagination and typographic detail.

Lindroth, Daniel; Tompuri, Markus; Ruponen, Pekka; Haruyama, Makoto; Alway, Aqmil

\section{Advanced Damage Stability Analyses for Design of Cargo Ships}

\section{Published in:}

Practical Design of Ships and Other Floating Structures - Proceedings of the 14th International Symposium, PRADS 2019 - Volume 1

DOI:

10.1007/978-981-15-4624-2_39

Published: 01/01/2021

Document Version

Peer reviewed version

Published under the following license:

Unspecified

Please cite the original version:

Lindroth, D., Tompuri, M., Ruponen, P., Haruyama, M., \& Alway, A. (2021). Advanced Damage Stability

Analyses for Design of Cargo Ships. In T. Okada, Y. Kawamura, \& K. Suzuki (Eds.), Practical Design of Ships and Other Floating Structures - Proceedings of the 14th International Symposium, PRADS 2019 - Volume 1 (Vol. 1, pp. 655-666). (Lecture Notes in Civil Engineering; Vol. 63 LNCE). SPRINGER. https://doi.org/10.1007/978981-15-4624-2 39

This material is protected by copyright and other intellectual property rights, and duplication or sale of all or part of any of the repository collections is not permitted, except that material may be duplicated by you for your research use or educational purposes in electronic or print form. You must obtain permission for any other use. Electronic or print copies may not be offered, whether for sale or otherwise to anyone who is not an authorised user. 


\title{
Advanced Damage Stability Analyses for Design of Cargo Ships
}

\author{
Daniel Lindroth $^{1 *}$, Markus Tompuri ${ }^{1}$, Pekka Ruponen ${ }^{1,2[0000-0002-0859-7783]}$, Makoto \\ Haruyama $^{3}$ and Aqmil Alway ${ }^{3}$ \\ ${ }^{1}$ NAPA, Helsinki, Finland \\ ${ }^{2}$ Aalto University, School of Engineering, Marine Technology, Espoo, Finland \\ ${ }^{3}$ NAPA Japan, Kobe, Japan \\ daniel.lindrothenapa.fi \\ markus.tompurienapa.fi \\ pekka.ruponen@napa.fi, pekka.ruponen@aalto.fi \\ makoto.haruyama@napa.fi \\ aqmil.alwayenapa.fi
}

\begin{abstract}
While the development of stability regulations mainly has been driven by the needs for passenger ships, cargo ships are also getting an update in the newly adopted amendments to the Safety of Life at Sea (SOLAS) convention. The stability at intermediate flooding stages have previously been ignored for cargo ships, but if the ship is equipped with cross-flooding devices, intermediate filling phases will now be evaluated. In this study, the relevancy of these intermediate stages for cargo ships is investigated. The focus is on a case study of a short sea ro-ro cargo ship with cross-flooding ducts in the double bottom. In addition to the conventional regulatory calculation methods, also time-domain flooding simulation is used for realistic assessment of intermediate stages and the actual time-to-flood. Such tools have previously been used for damage stability analyses of passenger ships. The different calculation methods are compared against each other through the attained subdivision index. The results indicate that cross-flooding improves damage stability also for cargo ships, and that simulation is an applicable tool also for design and analysis of safer ships.
\end{abstract}

Keywords: damage stability, cross-flooding, ro-ro cargo ship, SOLAS, simulation, progressive flooding.

\section{$1 \quad$ Background}

The research and evolution of stability regulations for ships has traditionally been focusing on passenger ships, and major accidents have been a driving force for the updates, as described in Francescutto and Papanikolaou [1]. Still, the safety level of cargo ships is not to be forgotten. The rapid capsizing and sinking of the PCTC (pure car and truck carrier) Baltic Ace after a collision damage in 2012, [2], emphasizes the need to ensure a good survivability in the case of transient flooding, especially for cargo ships with large open (ro-ro) decks. 
Previously, when the harmonized SOLAS 2009 regulations were introduced, Papanikolaou and Eliopoulou [3] stated that: "Dry Cargo Ro-Ro \& Car Carriers is the only ship type that will be significantly affected by the new probabilistic concept in that some existing designs are expected to face major problems with their compliance with the new levels".

According to Tagg [4], the new cargo ro-ro ships, including PCTCs, have a better survivability due to an increased freeboard height to meet the SOLAS 2009 requirements. However, flooding of a large lower cargo hold beneath the bulkhead deck both decreases the stability due to the free surface effect and decreases the residual freeboard, thus increasing the risk of flooding of the main cargo deck. For this reason, the lower hold is usually protected by void spaces and tanks on the sides, de Kat et al. [5]. The disadvantage of this design is a risk of asymmetric flooding and extensive heeling. This can fortunately often be avoided with efficient cross-flooding devices. In addition, complex arrangements with actively controlled counter-flooding devices have been developed for ro-ro ships, Yamato et al. [6].

In the SOLAS 2020 amendments, IMO Resolution MSC.421(98), [7], the intermediate flooding stage is now introduced also for cargo ships that are equipped with cross-flooding devices. The regulation states that "For cargo ships not fitted with cross-flooding devices the factor $s_{\text {intermediate }, i}$ is taken as unity, except if the Administration considers that the stability in intermediate stages of flooding may be insufficient, it should require further investigation thereof." Consequently, merely equipping a cargo ship with cross-flooding devices results in that intermediate flooding stages should be calculated and accounted for in the attained subdivision index.

For passenger ships, including ro-ro/passenger (RoPax) ships, detailed calculation of cross-flooding, and subsequent intermediate stages, is part of the normal damage stability analysis. Moreover, advanced tools, such as time-domain flooding simulation, have been used, e.g. Ruponen and Routi [8]. With the introduction of SOLAS 2020 amendments, such tools now become relevant also for the design of cargo ships.

The new regulations naturally aim at an increased survivability and safer ships, but what are the consequences following these updates for the designer? This study concentrates on the cross-flooding analyses for a short-sea cargo ro-ro vessel. Here the probabilistic damage stability results obtained using different calculation methods are compared to each other. The differences in the results are analyzed and discussed.

\section{Probabilistic Damage Stability}

The basic concept of probabilistic damage stability requirements in SOLAS Ch. II-1 is quite simple, and has remained unchanged between SOLAS 2009, [9], and SOLAS 2020 , [7]. The overall attained subdivision index must be greater or equal to the required subdivision index:

$$
A \geq R
$$


In addition, for each calculated draft (subscript $k$ ), the local attained index must be greater or equal to a fraction of the required index. For passenger ships the fraction is 0.9 and for cargo ships 0.5 , and therefore:

$$
A_{k} \geq 0.5 R
$$

For cargo ships, the required subdivision index depends on the subdivision length, and when $L_{s}>100 \mathrm{~m}$, it is:

$$
R=1-\frac{128}{L_{S}+152}
$$

It is noteworthy that, the required index for cargo ships is much lower than for passenger ships.

The overall attained subdivision index is obtained by summing the partial indices for the three drafts (subscripts $s, p$ and $l$ ) with their corresponding weight factors:

$$
A=0.4 A_{s}+0.4 A_{p}+0.2 A_{l}
$$

Each partial index is a summation of the contribution of all damage cases considered:

$$
A_{k}=\sum_{i} p_{i} s_{i}
$$

where $p_{i}$ is the probability of the damage case and $s_{i}$ represents the survivability level, accounting for the worst of the possible intermediate flooding stages and the final condition after flooding.

For intermediate flooding stages, the s-factor is defined as:

$$
S_{\text {intermediate }, i}=\left[\frac{G Z_{\max }}{0.05} \cdot \frac{\text { Range }}{7}\right]^{1 / 4}
$$

where $G Z_{\max }$ is not to be taken as more than $0.05 \mathrm{~m}$ and Range as not more than $7^{\circ}$. For cargo ships, the intermediate s-factor is set to zero if the heel angle exceeds $30^{\circ}$.

Similarly, for the final stage:

$$
S_{\text {final }, i}=K \cdot\left[\frac{G Z_{\max }}{0.12} \cdot \frac{\text { Range }}{16}\right]^{1 / 4}
$$

where $G Z_{\max }$ is not to be taken as more than $0.12 \mathrm{~m}$ and Range not more than $16^{\circ}$. The coefficient $K$ accounts for the heel angle $\theta$, and for cargo ships $K=0$ if the heel angle exceeds $30^{\circ}$, and $K=1$ if the heel angle is less than $25^{\circ}$, and otherwise:

$$
K=\sqrt{\frac{30^{\circ}-\theta}{5^{\circ}}}
$$

In practice, this means that $s_{i}=1$ can be achieved even if the heel angle is large, thus imposing a serious risk of cargo shift.

Note that the SOLAS 2020 introduction of a stricter s-factor for the final stage of flooding if a damage case involves a ro-ro space, only concerns RoPax vessels, and it is therefore not used for cargo ro-ro ships. 


\section{Cross-Flooding Calculations}

In order to ensure a rapid equalization of asymmetric flooding, cross-flooding devices, such as pipes and ducts can be used, as illustrated in Fig. 1. The explanatory notes, [10], state that: "Calculations for intermediate stages of flooding should be performed whenever equalization is not instantaneous, i.e. equalization is of a duration greater than $60 \mathrm{~s}$ ". Therefore, it is necessary to calculate the time that it takes to equalize the flooding since the situation after $60 \mathrm{~s}$ and $600 \mathrm{~s}$ should be considered.

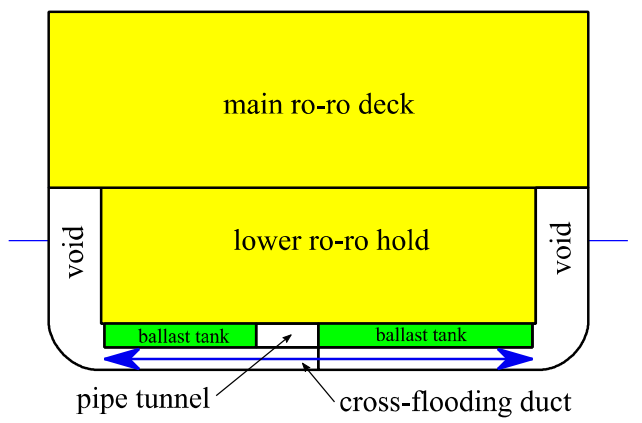

Fig. 1. Typical cross-flooding arrangement of a ro-ro ship.

A simplified calculation method for the cross-flooding time between two wing tanks was introduced by Solda [11] in 1961, and this approach has later been adopted by IMO. It is still included in the current recommendation, Resolution MSC.362(92), [12]. The cross-flooding time can be approximated with a simple formula:

$$
T_{f}=\frac{2 W_{f}}{S \cdot F} \cdot \frac{1}{\sqrt{2 g H_{0}}} \cdot \frac{1}{\left(1+\sqrt{\frac{h_{f}}{H_{0}}}\right)}
$$

where $W_{f}$ is the cross-flooded volume, $S$ is the effective area of the device and the flow reduction coefficient $F$ accounts for the pressure losses in the cross-flooding device. The initial pressure head of floodwater is $H_{0}$, and the pressure head at the end of cross-flooding is $h_{f}$. If the tank extends above the water level this equals to zero.

The coefficient $F$ can be evaluated experimentally, Stening et al. [13], or with CFD, Ruponen et al. [14]. However, in practical design work, the simplified regression equations for various typical duct and pipe arrangements in the appendix of MSC.362(92) can be applied. It is worth noting that this regulation contains some typos, and the correct formulae are given in MSC 92/11/2, [15].

The main drawback of this simplified method is that it cannot properly handle simultaneous cross-flooding in different compartments. Therefore, the use of timedomain flooding simulation provides more realistic results for cases with complex cross-flooding arrangements, Ruponen and Lindroth [16]. The methods are fully 
compatible since the same flow reduction coefficients for the cross-flooding devices can be used also in simulation.

Air compression in a flooded tank or void space can be notable, Ruponen et al. [17]. Therefore, inadequate ventilation of the flooded rooms can prevent rapid crossflooding, and therefore, efficient air pipes should be used, Ruponen and Routi [8].

\section{Case Study}

\subsection{Ship Design}

The studied ship design is a typical short-sea cargo ro-ro vessel, Fig. 2, used for example in the Baltic Sea, designed according to the SOLAS 2009 edition. The main dimensions are listed in Table 1, and the general arrangement is presented in Fig. 3.

Unprotected openings were modelled on top of the main ro-ro deck, representing the outlets of the ventilation pipes. Immersion angle of these openings was used to limit the range of stability in the calculation of the s-factors. Below the lower hold, there are cross-flooding ducts in six compartments. Up-flooding from the lower hold to the main ro-ro deck is prevented by a watertight hatch cover. The applied initial conditions are listed in Table 2.

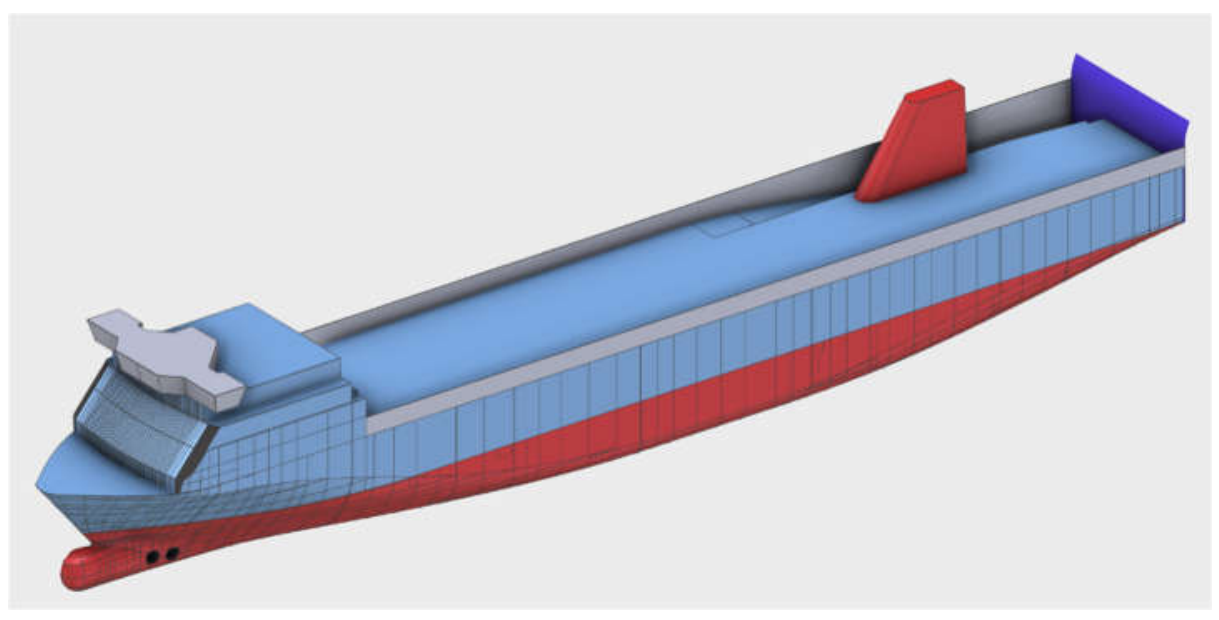

Fig. 2. 3D rendering of the studied short-sea ro-ro vessel.

Table 1. Main dimensions of the studied ro-ro vessel.

\begin{tabular}{lr}
\hline Length over all: & $180 \mathrm{~m}$ \\
Breadth: & $25 \mathrm{~m}$ \\
Design draft: & $6.00 \mathrm{~m}$ \\
Lane meters (approx.) & $2500 \mathrm{~m}$ \\
\hline
\end{tabular}




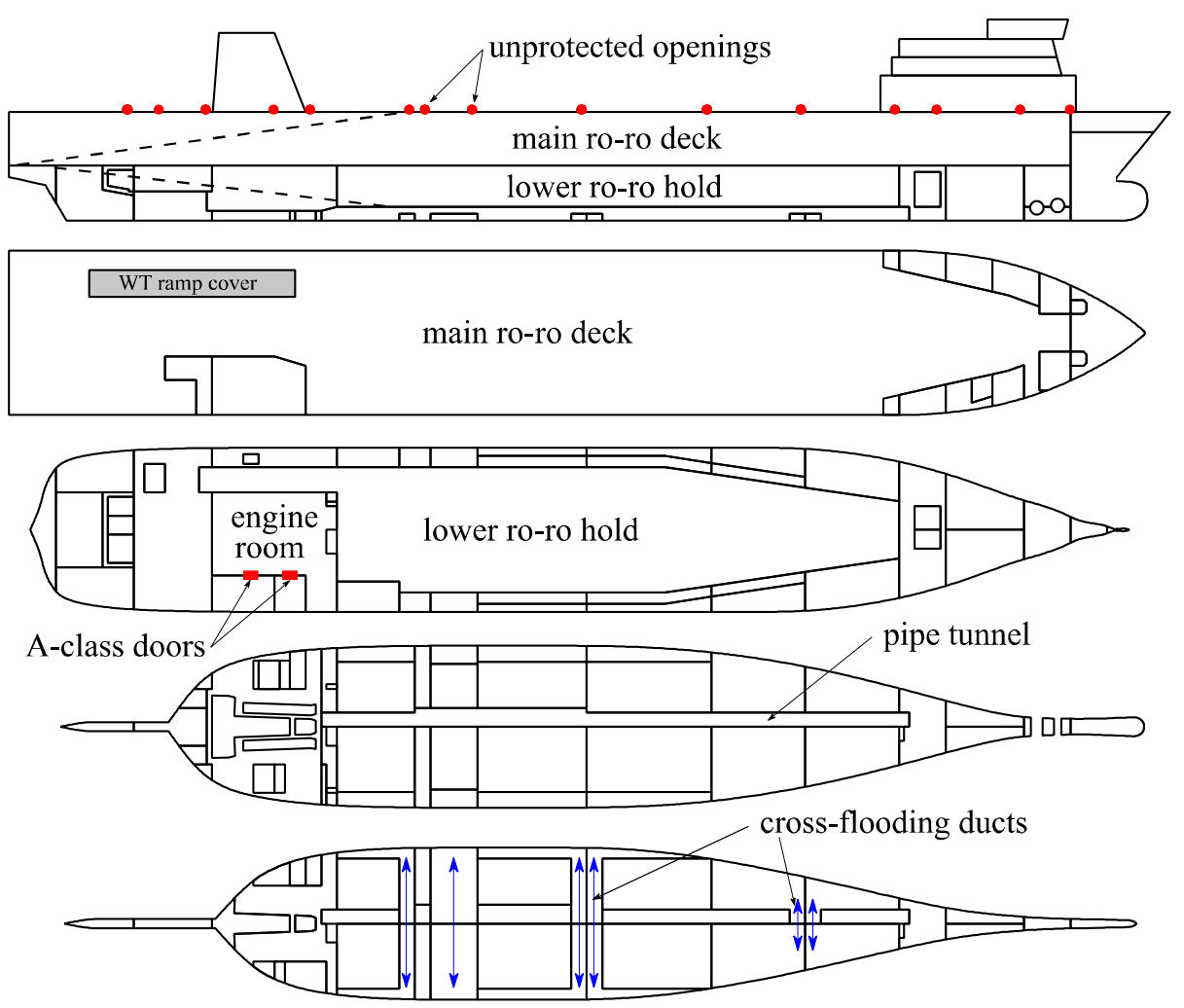

Fig. 3. General arrangement of the studied ro-ro vessel, including modelled openings and crossflooding ducts.

Table 2. Initial conditions for SOLAS calculations.

\begin{tabular}{llll}
\hline Initial condition: & Draft $(\mathrm{m}):$ & Trim $(\mathrm{m}):$ & GM $(\mathrm{m}):$ \\
\hline Deepest subdivision draft & 6.00 & 0.00 & 1.70 \\
Partial draft & 5.20 & 0.00 & 2.10 \\
Lightest & 4.00 & $0.75(\mathrm{aft})$ & 1.00 \\
\hline
\end{tabular}

\subsection{Calculations}

The reference results for the attained subdivision index were first calculated according to SOLAS 2009, where only the final equilibrium conditions were considered. Then the SOLAS 2020 regulation was applied, and intermediate stages were included in the subsequent calculations. For comparison, a design variation without cross-flooding devices was also studied. In this case, intermediate stages were not considered and asymmetric flooding was not equalized. Finally, the cases with intermediate stages due to cross-flooding or A-class doors in the engine room compartment were recalcu- 
lated using time-domain flooding simulation, similarly to the case study on the passenger ship, presented in Lindroth et al. [18].

All calculations were done with the NAPA software, and are summarized in Table 3. The applied flooding simulation method is described in Ruponen [19]. In the intermediate flooding phases, including all simulation time steps, the volumes of floodwater in the compartments remain constant during the calculation of the righting lever curve. This approach is described in detail in Ruponen et al. [20]. The compartments in way of damage were always treated as lost buoyancy. A constant time step of $5.0 \mathrm{~s}$ was applied, based on experience from a previous study, [16]. Additionally, a maximum heel limit of $30^{\circ}$ was applied to all time steps in the simulation, following the maximum allowed heel in the intermediate s-factor formula for cargo ships, see equation (8).

The machinery spaces are divided into smaller rooms by A-class fireproof boundaries. These structures are not watertight, and especially the doors leak and collapse under a moderate pressure head of about $2.0 \mathrm{~m}$. In the simulations, the leakage and collapse of the A-class hinged fire doors is accounted for, by using the parameters from the EU FP7 project FLOODSTAND, Jalonen et al. [21]. Intermediate stages with all possible combinations of intact and collapsed A-class boundaries are typically considered in conventional damage stability calculations for SOLAS. It is noteworthy, that according to the regulation [7], there is no need to evaluate the intermediate flooding stages if the ship is not equipped with cross-flooding devices.

Table 3. Summary of the applied calculation methods.

\begin{tabular}{|c|c|}
\hline Acronym: & Explanation: \\
\hline S2009 & $\begin{array}{l}\text { Conventional calculation according to SOLAS 2009, no } \\
\text { intermediate stages considered }\end{array}$ \\
\hline S2020 cross & $\begin{array}{l}\text { Conventional calculation according to SOLAS } 2020 \text {, } \\
\text { including intermediate stages due to cross-flooding, and } \\
\text { A-class structures in the engine room }\end{array}$ \\
\hline S2020 no cross & $\begin{array}{l}\text { Conventional calculation according to SOLAS } 2020 \text { for } \\
\text { a modified design without cross-flooding devices, and } \\
\text { consequently no intermediate stages }\end{array}$ \\
\hline S2020 sim & $\begin{array}{l}\text { All cases calculated with time-domain flooding simula- } \\
\text { tion, accounting for realistic intermediate stages of } \\
\text { flooding, in compliance with SOLAS } 2020 \text { explanatory } \\
\text { notes }\end{array}$ \\
\hline
\end{tabular}

\subsection{Results}

The subdivision length of the ship is $179 \mathrm{~m}$, and therefore required subdivision index for the studied ship is $R=0.61329$. The attained index with different calculation methods is presented in Fig. 4.

The ship was originally designed according to requirements of SOLAS 2009 regulation, and with this calculation method, the attained index is slightly larger than the 
required index. The new SOLAS 2020 amendments introduce calculation of intermediate flooding stages since the ship is equipped with cross-flooding devices. In many cases, these intermediate stages are more severe, and as a result, the attained index became smaller, slightly below the required index. If the cross-flooding devices are removed (S2020 no cross), asymmetric flooding is not properly equalized and the resulting A-index is notably smaller than with the cross-flooding devices (S2020 cross). With time-domain flooding simulation (S2020 sim), the attained index is larger than the required index, and thus the original design is proven to pass the SOLAS 2020 requirement.

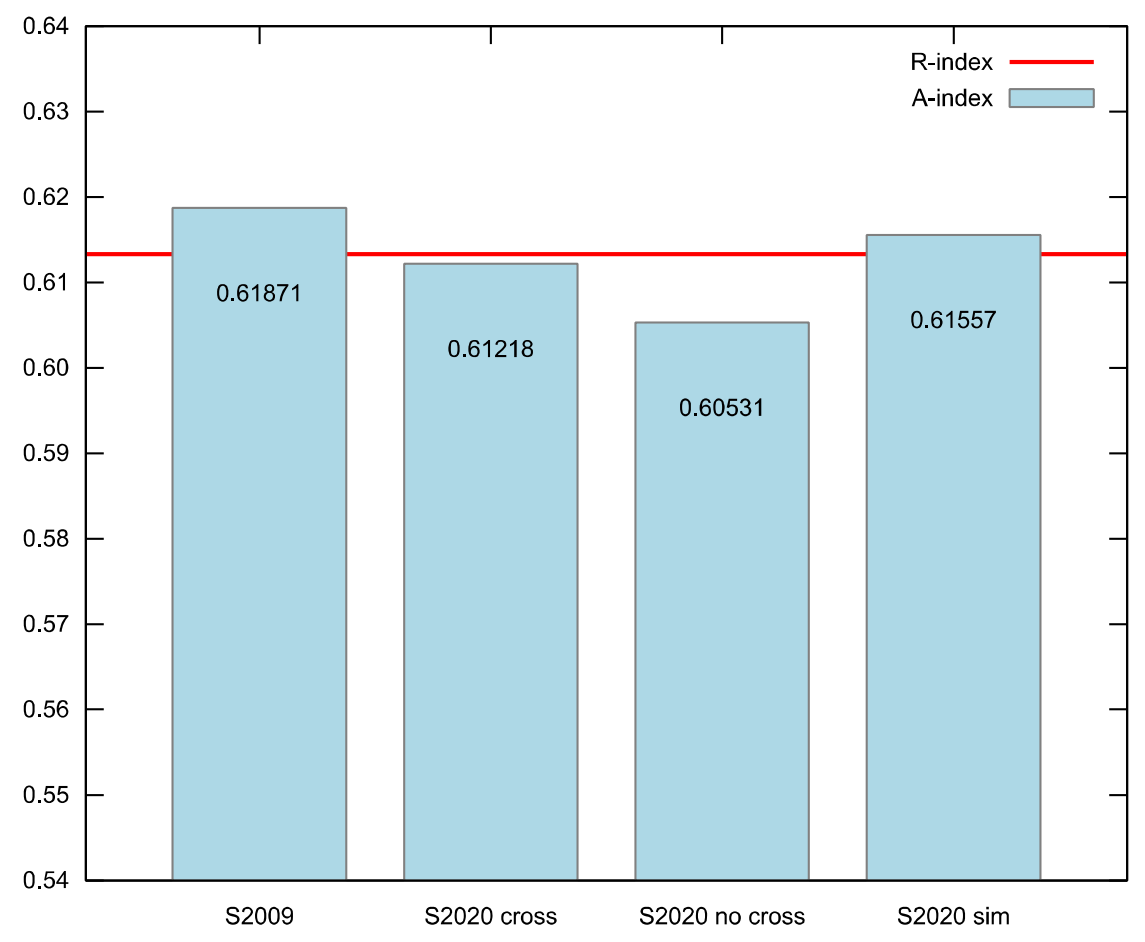

Fig. 4. Attained subdivision index with different calculation methods (see Table 3).

One case involving flooding of the engine room and the lower hold was selected for a more detailed analysis. The righting lever curves before progressive flooding through the A-class boundaries (stage 1) and at the final equilibrium condition are presented in Fig. 5. In the intermediate stage, stability is significantly reduced, but the equalizing cross-flooding notably improves the situation. The corresponding floating positions and flooded compartments are illustrated in Fig. 6.

Conventional calculation methods do not consider the time perspective, and the worst flooding stage is used for determining the effective s-factor. In this particular case the result is $s=0.7003$. With time-domain flooding simulation, using the stage 
1 as the first time step, it can be seen that the final condition is reached very rapidly, and the extensive heeling is equalized within $60 \mathrm{~s}$, Fig. 7, and according to the Explanatory Notes to SOLAS, [10], instantaneous flooding can be assumed. Consequently, a larger s-factor is obtained, namely $s=0.9298$. Although the increase of the s-factor is quite small, the actual improvement in the stability is quite notable, as illustrated in Fig. 5, and both the maximum righting lever and the range of positive stability are notably larger.

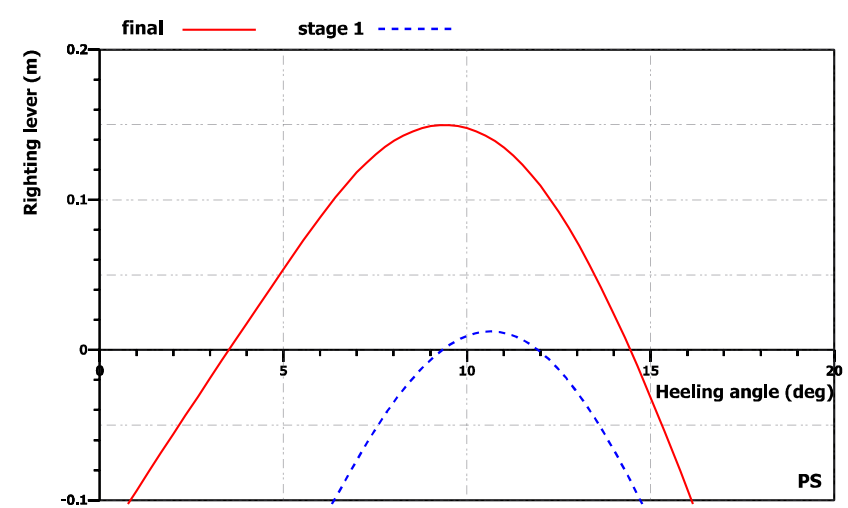

Fig. 5. Righting lever curves for a case, where stability is reduced in an intermediate flooding stage when compared to the final condition after flooding.

stage 1:
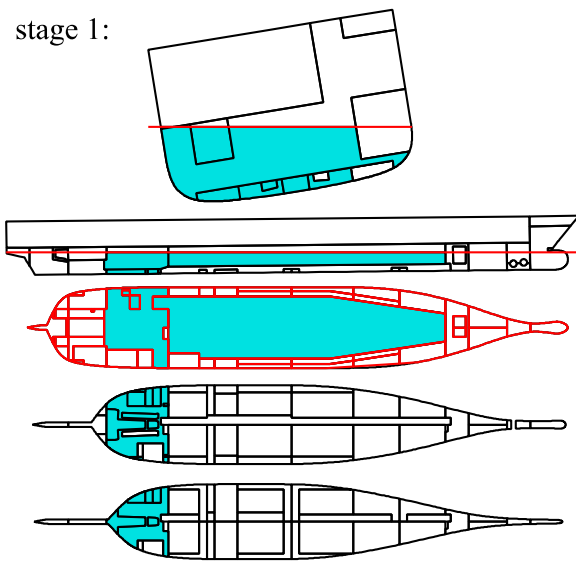

final:
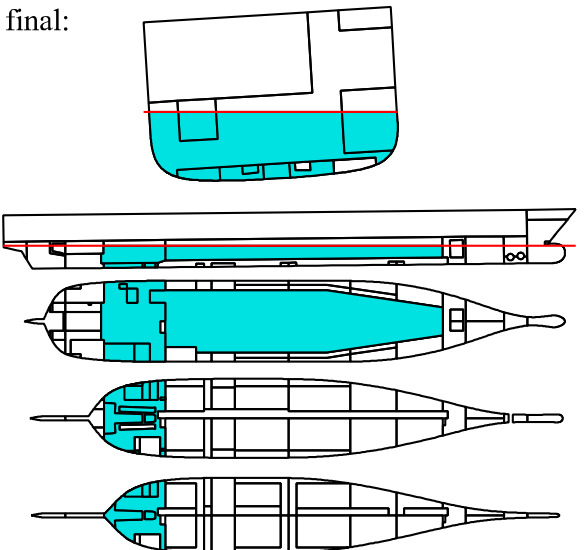

Fig. 6. Visualization of floating position and flooded compartments for the studied case; first stage with damaged compartments flooded (left) and final equilibrium (right). 


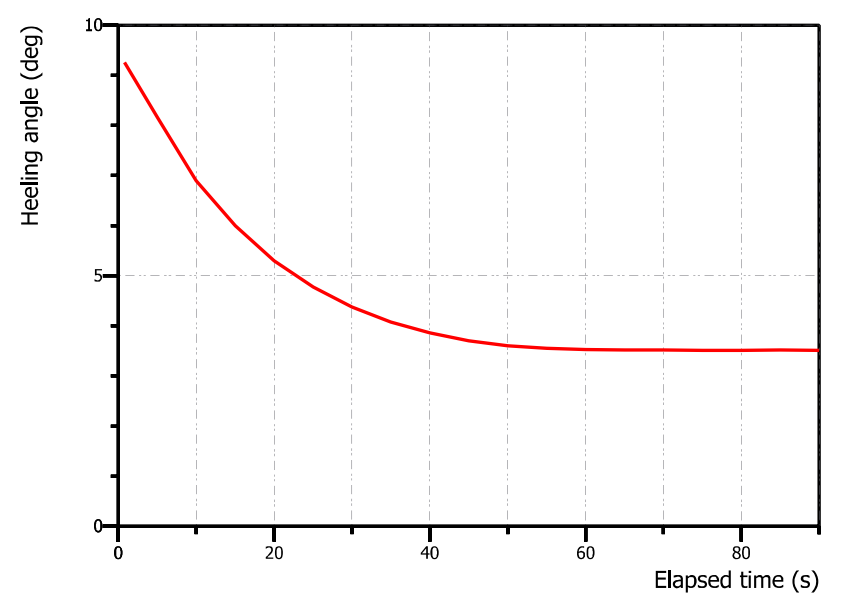

Fig. 7. Simulated time-history of heeling angle.

\section{Conclusions}

The governing physics for passenger and cargo ships are the same, and consequently it is important to consider the stability during intermediate flooding stages also for cargo vessels. This is especially true for ro-ro vessels with a large lower hold. In this respect, the latest SOLAS 2020 amendments are a step towards an improved safety level for cargo vessels. The studied example of the short-sea cargo ro-ro vessel demonstrated that the attained subdivision index is smaller with SOLAS 2020 than with SOLAS 2009 due to the introduction of intermediate flooding stages. In the studied case, the removal of the cross-flooding devices resulted in an even smaller attained index, which is reasonable since the cross-flooding is expected to improve the stability after damage in most cases.

It is noteworthy that the latest SOLAS amendments still gives a high s-factor even with a large angle of heel. Especially for ro-ro vessels, where the risk of cargo shift is present. As a result, the survivability may be significantly reduced, as pointed out e.g. in Spanos and Papanikolaou, [22]. Therefore, the use of cross-flooding devices to decrease the heeling is considered as an effective way to improve the safety of the flooded ship.

The conventional calculations according to SOLAS 2020 took about $2.5 \mathrm{~h}$, and simulation of all cases with a constant time step of $5.0 \mathrm{~s}$ took about $6 \mathrm{~h}$ with a typical business laptop (Intel ${ }^{\circledR}$ Core ${ }^{\mathrm{TM}}$ i7-7820HQ @ 2.9GHz with $24 \mathrm{~GB}$ of RAM). Timedomain flooding simulation is a useful tool for analysis of the time-to-flood, even in complex cases involving simultaneous cross-flooding and progressive flooding through openings or A-class doors. This approach is also recognized as an alternative method in the explanatory notes to SOLAS 2020, [10]. The simulation of intermediate flooding stages can also be combined with an optimization algorithm, as presented in Manderbacka et al. [23], in order to maximize both the cargo capacity, and survival in case of damage. 
Use of advanced tools, such as time-domain flooding simulation, enables realistic assessment of flooding progression and damage stability during these intermediate stages. Therefore, the design improvements can be focused on factors that affect damage stability, such as efficient cross-flooding arrangement. Consequently, these tools can be used to design safer cargo ships.

\section{References}

1. Francescutto A., Papanikolaou A.D.: Buoyancy, Stability, and Subdivision: From Archimedes to SOLAS 2009 and the Way Ahead. Proceedings of the Institution of Mechanical Engineers, Part M: Journal of Engineering for the Maritime Environment, 225(1):17-32 (2011). https://doi.org/10.1177/14750902JEME238

2. The Bahamas Maritime Authority: Report of the investigation into the loss of m.v Baltic Ace following a collision with m.v Corvus J at the North Hinder Junction Precautionary Area on the 5th December 2012 (2016).

3. Papanikolaou A., Eliopoulou E.: On the development of the new harmonised damage stability regulations for dry cargo and passenger ships, Reliability Engineering and System Safety 93:1305-1316 (2008). https://doi.org/10.1016/j.ress.2007.07.009

4. Tagg R.: Comparison of survivability between SOLAS 90/95 and SOLAS 2009 ships - A retrospective view 10 years on from project HARDER, Proceedings of the 14th International Ship Stability Workshop, Kuala Lumpur, Malaysia (2014).

5. de Kat, J., Kanerva, M., van't Veer, R., Mikkonen, I.: Damage Survivability of a New RoRo Ferry, Proceedings of the 7th International Conference on Stability of Ships and Ocean Vehicles, Launceston, Tasmania, Australia (2000).

6. Yamato, K., Uemura, Y., Onzuka, M.: Development of "Stability Recovery System" that Maintains Ship Stability at the Time of Damage Ensuring Cargo Loading Capacity and Easing Restrictions on the Hull Form, Mitsubishi Heavy Industries Technical Review 50:2:33-36 (2013).

7. IMO: Resolution MSC.421(98) Amendments to the International Convention for the Safety of Life at Sea, 1974, as amended, Adopted on 15 June 2017 (2017).

8. Ruponen P., Routi A-L.: Design method for efficient cross-flooding arrangements on passenger ships, Marine Design XIII (eds. Kujala \& Lu), 13th International Marine Design Conference (IMDC2018). June 11-14 2018, Helsinki, Finland, pp. 709-718 (2018).

9. IMO: Resolution MSC.216(82) Adoption of Amendments to the International Convention for the Safety of Life at Sea, 1974, as Amended, Adopted on 8 December 2006 (2006).

10. IMO: Resolution MSC.429(98) Revised Explanatory Notes to the SOLAS Chapter II-1 Subdivision and Damage Stability Regulations, Adopted on 9 June 2017 (2017).

11. Solda, G.S.: Equalisation of Unsymmetrical Flooding, RINA Transactions, Vol. 103, pp. 219-225 (1961).

12. IMO: Resolution MSC.362(92) Revised Recommendations on a Standard Method for Evaluating Cross-Flooding Arrangements, Adopted on 14 June 2013 (2013).

13. Stening, M., Järvelä, J., Ruponen, P., Jalonen, R.: Determination of discharge coefficients for a cross-flooding duct, Ocean Engineering 38:570-578 (2011). https://doi.org/10.1016/j.oceaneng.2010.12.004

14. Ruponen, P., Queutey, P., Kraskowski, M., Jalonen, R., Guilmineau, E.: On the calculation of cross-flooding time, Ocean Engineering, Vol. 40:27-39 (2012). https://doi.org/10.1016/j.oceaneng.2011.12.008 
15. IMO: MSC 92/11/2 Modification of the revised regression formulae for cross-flooding through a series of structural ducts with 1 and 2 manholes in resolution MSC.245(83), submitted by Japan and Finland, 23 April 2013 (2013).

16. Ruponen, P., Lindroth, D.: Time-Domain Simulation for Regulatory Flooding Analysis, Proceedings of PRADS2016, 4-8 September 2016, Copenhagen (2016).

17. Ruponen, P., Kurvinen, P., Saisto, I., Harras, J.: Air compression in a flooded tank of a damaged ship, Ocean Engineering 57:64-71 (2013). https://doi.org/10.1016/j.oceaneng.2012.09.014

18. Lindroth, D., Ruponen, P., Tompuri, M.: Application of Flooding Simulation for a Detailed Analysis of SOLAS Damage Stability Results, Proceedings the 13th International Conference on the Stability of Ships and Ocean Vehicles STAB 2018, Kobe, Japan, 16-21 September 2018, pp. 608-615 (2018).

19. Ruponen, P.: Adaptive time step in simulation of progressive flooding, Ocean Engineering 78:35-44 (2014). https://doi.org/10.1016/j.oceaneng.2013.12.014

20. Ruponen, P., Manderbacka, T., Lindroth, D.: On the calculation of the righting lever curve for a damaged ship, Ocean Engineering 148:313-324 (2018). https://doi.org/10.1016/j.oceaneng.2017.12.036

21. Jalonen, R., Ruponen, P., Weryk, M., Naar, H., Vaher, S.: A study on leakage and collapse of non-watertight ship doors under floodwater pressure, Marine Structures 51:188-201 (2017). https://doi.org/10.1016/j.marstruc.2016.10.010

22. Spanos, D., Papanikolaou, A.: On the time dependence of survivability of ROPAX ships, Journal of Marine Science and Technology 17(1):40-46 (2012). https://doi.org/10.1007/s00773-011-0143-0

23. Manderbacka, T., Ruponen, P., Lindroth, D., Tompuri, M.: Subdivision Optimization of LNG Fueled Ropax Ship, in Proceedings of the 6th International Maritime Conference on Design for Safety, Hamburg, Germany, 28-30 November 2016, pp. 90-97 (2016). 